\title{
The manipulation of color response times in a color-word interference task
}

\author{
COLETTE RAY \\ University College, Cardiff, South Wales, United Kingdom
}

\begin{abstract}
The relationship between word and color response times and color-word interference is of theoretical importance for understanding the interference phenomenon. In this experiment, color response times were manipulated by varying the size of the color-word set, but there was no corresponding change in interference. Since the manipulation of word response times consistently leads to such changes, this result has certain implications which were briefly discussed.
\end{abstract}

In a color-word interference task, the $S$ is asked to name the color in which a word is written, ignoring the meaning of the word. In the standard situation, the color and the word are incongruous, for example the word "blue" may appear in green, the latter being the required response. The presence of the incongruous word disrupts performance in that color naming is longer for a color-word stimulus than for a patch of color, and more errors are associated with the former. This phenomenon was first noted by Jaensch (1929) and forms the basis of a test which was introduced to psychology by Stroop (1935). In this test, the $S$ is required to read a series of words, name the colors of color patches, and name the colors of incongruous color-words. An interference score can be derived by subtracting the time taken to name the colors of the control stimuli from that taken to name the colors of the stimuli in the interference condition. The color-word interference test has been used in a variety of contexts, including the study of drug effects and arousal, perceptual styles, and personality and developmental variables (see Jensen \& Rohwer, 1966, for a comprehensive review). Recent studies, however, have placed more emphasis upon the cognitive processes involved in the task itself and have varied the standard interference situation to determine the influence of such factors as the degree of association of the word and the color dimensions, and the recognizability of the words.

Interference will occur even when the response evoked by the word is not a color name, but the degree of interference is a function of the semantic relation between the irrelevant word dimension and the relevant color responses. Klein (1964) found that "neutral" words such as put, heart, take, and friend delayed the color response, but greater disruption was caused by color-associated words such as grass, sky, lemon, and fire; maximum interference was produced by color names which correspond with the colors used for the print. The level of association of the words with the relevant color responses was not the only factor to influence the degree of interference; where the words used were neutral (i.e., not color-related), high-frequency words caused a greater delay than low-frequency words. These results have been replicated by Fox, Shor, and Steinman (1971). It seems that association and frequency are orthogonal factors which together determine the interference potential of the word dimension (Scheibe, Shaver, \& Carrier, 1967).

It is well established that the recognition thresholds for high-frequency words are lower than those for low-frequency words (Solomon \& Howes, 1951); it can be argued that high-frequency words have a greater interference potential because they are associated with lower response times, and studies which have manipulated variables other than frequency support this interpretation. Bakan and Alperson (1967) compared the interference effects of three sets of nonsense syllables, which varied in pronunciability. The ordering of interference scores was found to correspond with the latter. A group of meaningful words was included in the study, and these produced more interference than any group of nonsense syllables, even where pronunciability was constant. It was shown that the ordering of groups in terms of interference scores was in perfect correspondence with the mean threshold of recognition for each group. Gumenik and Glass (1970) manipulated the recognizability of the irrelevant words by introducing a mask which made the words less legible; the presence of this mask weakened the reading response while leaving the color naming response unaffected, and the disruptive effect of the words was reduced. It has also been found that preexposure of a word up to $60 \mathrm{msec}$ before the color is presented enhances interference (Dyer, 1971), such preexposure being analogous to reducing the response time for the word.

The degree of interference produced by the word dimension can thus be effectively altered by manipulating the ease of recognition of the words. The effect of color response times on interference is less well established. In a study by Hock and Egeth (1970), in which color stimuli were responded to on the basis of whether or not they belonged to a target set of colors, the time taken to respond "yes" or "no" was found to vary with the size of the target set, but there was no 
interaction between this variable and interference. It might be argued from this that interference is not affected by the speed of the color response; it would, however, be unwise to generalize conclusions from this modified task to the standard color naming interference situation. It has been suggested (Dalrymple-Alford \& Azkoul, 1972) that the Ss in this study may have covertly named the color before making a comparison with the target set of color names in memory. If this were the case, then interference would have operated at the stage of covert verbalization of the color rather than at that of memory comparison, and the results would then merely indicate that interference in color naming was unaffected by the speed of performing a subsequent matching operation. Even without this cirticism, it is only with extreme caution that the results of Hock and Egeth's study might be applied to the standard color naming task. There is some evidence that the processes involved in the latter are more complex than those involved in tasks, such as memory comparison, which do not require verbal identification of the color (Uleman \& Reeves, 1971).

Dyer (1970) has attempted to assess the influence of both word and color response times upon interference, and in this study the Ss were required to name the colors vocally. The background luminance against which color words and control stimuli were presented was varied, and was found to affect both word and color response times. It was thus not possible to assess the effects of either of these on interference independently, but a significant correlation between interference and the ratio of word and color response times was obtained for the color name condition. There was an insignificant (and negative) relationship for the condition in which the irrelevant words were unrelated to color, and the results of this study are thus somewhat inconclusive with regard to the influence of color processing times per se.

The present study was designed to examine further the effects of manipulating color-naming time, in this case by varying the size of the color-word set from which stimuli were drawn (in Hock and Egeth's study it was the size of the target set, and not the range of stimuli presented, which was varied). According to Merkel's principle (1885), choice reaction time increases with the size of the stimulus set; however, where the stimulus-response association involved is a highly "compatible" one, this is no longer the case (Posner, 1966). Such a relationship seems to exist where the stimuli are words and the response demanded is one of verbal identification, and the speed of reading a word is independent of the size of the stimulus set (Pierce and Karlin, 1957; Conrad, 1962). Fraisse (1964) used sets of two, four, and eight words and found that verbal reaction time increased only very slightly with set size, whereas when the stimuli used were colors large differences were found between the conditions. He found that color naming time was always greater than word reading time, except when the size of the stimulus set was reduced to two. Similar results were obtained by Gholson and Hohle (1968a), who compared the effect of list length on the verbal identification of hues with that on hue names. The response time for the hue names was found to vary slightly with the range of potential stimuli, while that associated with the attribute of hue was considerably affected. Again, an interaction between list length and the type of stimulus was found, indicating that at list lengths of four and six, the reaction times for hue names were shorter than those for hues, while at a list length of two the means were actually reversed.

The stimuli employed in the experiment reported here were incongruous color words, and the size of the stimulus set was varied to produce differences in color response time; such a manipulation should not significantly affect the speed of response to the word dimension. It was predicted that reducing the size of the stimulus set would result in shorter color naming in the control conditions, and that the delay in color naming produced by the words in the interference conditions would be less for the set size associated with the shorter color response time: since the color naming task is more prone to disruption when the irrelevant dimension is easily processed, faster processing of the relevant dimension would be expected to have the reverse effect.

\section{METHOD}

Subjects

Six teen undergraduate students, eight males and eight females, took part in the experiment.

\section{Stimuli and Apparatus}

A Carousel projector was used to present slides onto a ground glass screen, which was viewed by the $S$ from a distance of $8 \mathrm{ft}$. The latency of vocal response to the slides was measured by means of a throat microphone which was linked with a digital timer, set to start simultaneously with presentation of a slide. The voice key also activated the slide change mechanism of the projector. Thus, when the $S$ named the color of the slide, activation of the voice key stopped the timer, the slide was rejected, the timer reset, and the next slide in the series presented. The time taken for this slide change was $1.2 \mathrm{sec}$.

Colored Letraset was used to construct the slides. In the control conditions (C), the stimuli were colored circles; for the interference conditions ( $\mathrm{CW}$ ), color names in incongruously colored print were presented. Two set sizes were used for both the control and the interference conditions. In the smaller set of three colors, red, green, and black were used for both the colors and the words; for the larger set, the stimuli were drawn from a range of five colors-red, green, yellow, blue, and black.

There were thus four different conditions: C3: colored circles in red, green, and black; $C 5$ : colored circles in red, green, black, yellow, and blue; CW3: incongruously associated colors and color names from the same range as the $\mathrm{C} 3$ condition; and CW5: incongruously associated colors and color names drawn from the same range as the $C 5$ condition. It was considered necessary to balance the sequential effects known to exist when two adjacent color-word stimuli involve the same color, whether as the word or as the color dimension (Sichel \& Chandler, 1969). It was not possible to eliminate these in the CW3 condition where there were only three colors available. There are four possible sequential relationships which will affect the degree of interference for a particular stimulus-where the irrelevant word or the relevant color response is the same as for the preceding 
color-word stimulus; where the irrelevant word refers to the color of the preceding stimulus; and where the relevant color response is the color name which has been suppressed for the last response made. The stimuli were arranged so that these different types of sequential relationships occurred the same number of times in both the CW3 and CW5 conditions. The control colors were arranged in the same order as their corresponding color-word condition. There were 20 slides for each of four conditions, with five practice slides being shown before each series was presented.

\section{Procedure}

All Ss received the four conditions, C3, CW3, C5, and CW5. The control conditions, $\mathrm{C} 3$ and $\mathrm{C} 5$ were presented immediately before the $\mathrm{CW}$ conditions with which they were associated. The order of presentation of the stimuli drawn from the two different set sizes was alternated between Ss, i.e., the order of conditions for each $\mathrm{S}$ was either $\mathrm{C} 3, \mathrm{CW} 3 / \mathrm{C} 5, \mathrm{CW} 5$ or $\mathrm{C} 5$, $\mathrm{CW} 5 / \mathrm{C} 3, \mathrm{CW} 3$. Before presentation of a series, the $\mathrm{S}$ was told which colors would appear, and was asked to name the color of each slide as quickly as possible. Before presentation of an interference condition, the nature of the stimuli was explained; the $S$ was told that the colors would be the same as those in the preceding series of slides and that the color names would refer to these colors; he was told to ignore the words and name the color of the lettering as quickly as possible without making errors.

\section{RESULTS}

In the very rare cases in which errors were made, the average response time for that condition was substituted for the error score. The mean response times for the 20 slides within each series were obtained for each $\mathrm{S}$, resulting in four sets of scores, $\mathrm{C} 3, \mathrm{C} 5, \mathrm{CW} 3$, and $\mathrm{CW} 5$; from these measures, interference scores $(\mathrm{CW}-\mathrm{C})$ were derived for each set size. These values are presented in Table 1. The response times for the color stimuli alone were shorter when the set size was three than when it was five, and this difference was significant at the .01 level of confidence. The color-word response times were also significantly different $(\mathrm{p}<.05)$. The interference scores, however, showed a difference in the opposite direction to that predicted, although this difference was small and not significant.

\section{DISCUSSION}

Changing the size of the color set was an effective means of changing the time taken to name colors within that set: the smaller the set, the faster was the response. This directly influenced the time taken to name the color in the presence of an incongruous word, and these results support those of Gholson and Hohle (1968b) who also found that the reaction time for color words increased with list length. No interference scores were obtained in the Gholson and Hohle experiment, its purpose being different from that of the present study. The control stimuli used were colored anagrams of color names and, since such stimuli will also disrupt production of a color naming response, it would have been impossible to derive true interference scores from the data. In the present experiment, interference scores were derived, but they were found to be unaffected by
Table 1

Response Times and Interference Scores (in Milliseconds) for the Two Set Size Conditions

\begin{tabular}{clccc}
$\begin{array}{c}\text { Size at } \\
\begin{array}{c}\text { Stimulus } \\
\text { Set }\end{array}\end{array}$ & $\begin{array}{c}\text { Color } \\
\text { Naming } \\
\text { (C) }\end{array}$ & $\begin{array}{c}\text { Color Nam- } \\
\text { ing of Word } \\
\text { (CW) }\end{array}$ & $\begin{array}{c}\text { Inter- } \\
\text { ference } \\
\text { (CW-C) }\end{array}$ \\
\hline & Mean & 715 & 863 & 149 \\
3 & SD & 106 & 128 & 135 \\
& Mean & 783 & 926 & 143 \\
5 & SD & 89 & 121 & 110 \\
\hline
\end{tabular}

the size of the color set, thus indicating that the interference potential of the word dimension is not influenced by the ease of color naming.

These results were confirmed by those of a subsequent experiment (unpublished), in which color response times were manipulated by varying the "codability" oî the colors used rather than the set sizes from which the stimuli were drawn. In one condition, the colors were all primary, while in a second condition, the colors selected were less common. The data showed that these two color sets were indeed associated with significantly different response times for color control stimuli. The words used were not color names, but words unrelated to color, and two levels of word frequency were employed to produce differences in word reading time between these conditions. A significant difference in the interference produced by the two word sets was found, but again the variation in color response times failed to influence interference scores. As in the present study, the insignificant difference was not even in the direction predicted by the hypothesis.

The influence of color and word-response times is of great theoretical importance in understanding the processes involved in color-word interference. The most prominent explanations of the interference phenomenon are based on either perceptual conflict or response competition. The former assume a limited processing capacity with the word dimension being primary (e.g., Hock \& Egeth, 1970), so that the presence of the word distracts from encoding of the color dimension. In order to account for the influence of word response times on interference, such an explanation would assume that easily recognizable words preempt attention to a greater extent. The perceptual conflict hypothesis would not, however, necessarily predict that slower color naming would lead to more interference. On the other hand, response competition theories which assume parallel processing, (e.g., Morton, 1969), state that a color-word stimulus will elicit interference whenever the response associated with the word becomes available before the relevant color response. It takes less time to read a color name than to name a color, so that the word response for the color-word stimulus would generally be processed before the appropriate color response; when this occurs production of the latter would be temporarily inhibited, since it is assumed that only one 
response can become available at a time. Within this framework, the tendency for the word response to precede that for the color would depend upon the recognizability of the word, together with the response latency associated with the color. Both word and color response times should be influential in determining the degree of interference, since it is the relative ease of responding to the word and color dimensions which is held to be of prime importance.

The results of the present experiment would suggest that, within the context of a color naming task, it is the absolute speed of response for the word dimension alone which influences interference. Where the color must be identified, the extent of disruption induced by the presence of words, and the consequent delay in color naming, is influenced by the ease of word reading, but not by the ease of color naming. The absence of a color response time effect is incompatible with a theory of interference based upon parallel processing of the words and colors, where disruption is assumed to be a function of the likelihood of a word response becoming available before that for the color. The extent of delay produced by the word dimension is solely dependent upon the ease with which the tendency to read the words may be suppressed, and this finding supports Hock and Egeth's view that it is the primary nature of the word reading response which essentially disrupts color naming, rather than the fact that specific word responses tend to be faster than those for color.

It should, however, be noted that only two color conditions were employed in this study, and it might be profitable to carry out a further experiment, incorporating several conditions, which would produce finer variations in color response time. The study by Dyer (1971), mentioned in the introduction, found that preexposing the word of a color-word stimulus 40 to $60 \mathrm{msec}$ before coloration served to increase interference while with longer preexposures interference progressively declined. It might be argued that increasing the time taken to name the color of a color word would have the same effect as preexposing the word, in that the response time difference between the word and color response would be increased. If this were the case, an increase in color response time of more than $60 \mathrm{msec}$ might serve to decrease interference, while increased interference might be observed where the color response was delayed by less than this amount. The results, however, indicate that the response time difference between the two color sets in this experiment did not greatly exceed this value. Moreover, the assumption that word preexposure is equivalent to manipulation of color response times is questionable: the standard color-word interference task involves simultaneous presentation of the incongruous stimulus aspects; the situation in which the irrelevant aspect is first presented separately, with response time being measured from presentation of the relevant aspect, will involve factors different from those of the standard situation.

\section{REFERENCES}

Bakan, P., \& Alperson, B. Pronounceability, attensity, and interference in the color-word test. American Journal of Psychology, 1967, 80, 416-420.

Conrad, R. Practice, familiarity, and reading rate for words and nonsense syllables. Quarterly Journal of Experimental Psychology, 1962, 14, 71-76.

Dalrymple-Alford, E. C., \& Azkoul, J. The locus of interference in the Stroop and related tasks. Perception \& Psychophysics, 1972, 11, 385-388.

Dyer, F. N. Word reading, color naming and Stroop interference as a function of background luminance. USAMRL Report, 1970, No. 889.

Dyer, F. N. The duration of word meaning responses: Stroop interference for different preexposures of the word. Psychonomic Science, 1971, 25, 229-231.

Fox, L. A., Shor, R. E., \& Steinman, R. J. Semantic gradients and interference in naming color, spatial direction and numerosity. Journal of Experimental Psychology, 1971, 91, 59-65.

Fraisse. P. Le temps de réaction verbale. L'Année Psychologique, $1964,64,21-46$

Gholson, B., \& Hohle, R. H. Verbal reaction times to hues vs hue names and forms vs form names. Perception \& Psychophysics, $1968 \mathrm{a}, 3,191-196$.

Gholson, B., \& Hohle, R. H. Choice reaction time to hues printed in conflicting hue names and nonsense words. Journal of Experimental Psy chology, 1968b, 76, 413-418.

Gumenik, W. E.* \& Glass, R. Effects of reducing the readability of the words in the Stroop Color-Word Test. Psychonomic Science, 1970, 20, 247-248.

Hock, H. S., \& Egeth, H. Verbal interference with encoding in a perceptual classification task. Journal of Experimental Psychology, 1970, 83, 299-303.

Jaensch, E. R. Grundformen menschlichen Seins. Mit Perucksichtigung ihrer Beziehungen zu Biologie und Medizin, zu Kulturphilosophie und Padagogik. Berlin: Otto Elsner, 1929 .

Jensen, A. R., \& Rohwer, W. D., Jx. The Stroop Color-Word Test: A review. Acta Psychologica, 1966, 25, 36-93.

Klein, G. S. Semantic power measured through the interference of words with color naming. American Journal of Psychology, 1964, 77, 576-588.

Merkel, J. Die zeitlichen Verhaltniesse der Willensthatigkeit. Philosophische Studien, 1885, 2, 73-127.

Morton, J. Categories of interference: Verbal mediation and conflict in card sorting. British Joumal of Psychology, 1969, $60,329-346$.

Pierce, J. R., \& Karlin, J. E. Reading rates and the information rate of a human channel. Bell System Technical Journal, $1957,36,497-516$.

Posner, M. I. Components of skilled performance. Science, 1966 $152,1712-1718$.

Scheibe, K., Shaver, P. R., \& Carrier, S. C. Color association values and response interference on variants of the Stroop test. Acta Psychologica, 1967, 26, 286-295.

Sichel, J. L., \& Chandler, K. W. The color-word interference test: The effects of varied color-word combinations upon verbal response latency. Journal of Psychology, 1969, 72, 219-231.

Solom on, R. L., \& Howes, D. H. Word probability, personal values, and visual duration thresholds. Psychological Review, $1951,58,256-270$.

Stroop, J. R. Studies of interference in serial verbal reactions. Journal of Experimental Psy chology, 1935, 18, 643-662.

Uleman, J. S., \& Reeves, $J$. A reversal of the Stroop interference effect through scanning. Perception \& Psychophysics, 1971.9, 293-295.

(Received for publication March 28, 1973; final revision received March $4,1974$. ) 